Etnográfica

Revista do Centro em Rede de Investigação em

Antropologia

vol. 17 (2) | 2013

Vol. 17 (2)

\title{
Sónia Vespeira de Almeida, Camponeses, Cultura e Revolução: Campanhas de Dinamização Cultural e Acção Cívica do M. F. A. (1974-1975)
}

Sofia Sampaio

\section{(2) OpenEdition}

\section{Edição electrónica}

URL: https://journals.openedition.org/etnografica/3171

DOI: 10.4000/etnografica.3171

ISSN: 2182-2891

\section{Editora}

Centro em Rede de Investigação em Antropologia

Edição impressa

Data de publição: 1 junho 2013

Paginação: 423-427

ISSN: 0873-6561

\section{Refêrencia eletrónica}

Sofia Sampaio, «Sónia Vespeira de Almeida, Camponeses, Cultura e Revolução: Campanhas de

Dinamização Cultural e Acção Cívica do M. F. A. (1974-1975)», Etnográfica [Online], vol. 17 (2) | 2013, posto online no dia 20 junho 2013, consultado o 11 fevereiro 2022. URL: http://journals.openedition.org/ etnografica/3171 ; DOI: https://doi.org/10.4000/etnografica.3171

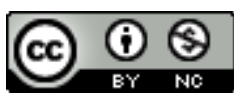

Etnográfica is licensed under a Creative Commons Attribution-NonCommercial 4.0 International License. 
Sónia Vespeira de Almeida

CAMPONESES, CULTURA

E REVOLUÇÃO: CAMPANHAS DE DINAMIZAÇÃO CULTURAL E ACÇÃO CÍVICA DO M.F.A. (1974-1975)

Lisboa, Edições Colibri e IELT

- Instituto de Estudos de Literatura

Tradicional, 2009, 418 páginas, ISBN: 978-972-772-882-4.

Quando, na noite de 24 para 25 de abril de 1974, um grupo de capitães das Forças Armadas deu início ao golpe que levaria ao derrube de um dos mais longos regimes autoritários da Europa, dificilmente poderia antever a profusão de movimentos e contramovimentos políticos e culturais que se lhe seguiriam. Os dois anos seguintes ficariam conhecidos por intensas mobilizações - foram os anos da "nação em movimento" (a expressão é de José Cardoso Pires, cit. p. 60), do Portugal em "trânsito" (para a democracia, na altura um termo "flutuante", com um conteúdo semântico fortemente disputado) ou mesmo "em transe" (cf. José Medeiros Ferreira, História de Portugal: Portugal em Transe, 1993). Este último termo não deixa de evocar um certo sentido de irrealidade, ou suspensão da normalidade, sobretudo quando experienciado a um nível mais subjetivo. Mas o que é realmente enfatizado em todas estas expressões é a súbita mobilização da sociedade portuguesa, em flagrante contraste com os anos de imobilismo e "paradismo" associados ao regime de Salazar. Entre as várias "movimentações”, tiveram um lugar de destaque as Campanhas de Dinamização Cultural e Ação Cívica levadas a cabo pelo Movimento das Forças Armadas (MFA), que constituem o tema deste livro, resultado de uma tese de doutoramento em antropologia apresentada, em 2008, ao Instituto Superior de Ciências do Trabalho e da Empresa (ISCTE).

Não é tarefa nada fácil falar destas campanhas, que continuam envoltas no ruído das opiniões ideologicamente marcadas, oscilando entre o ceticismo, ou até a desvalorização sumária, e uma celebração quase mistificadora. O que a autora nos propõe, pelo contrário - e com algum sucesso - é uma "descida" ao terreno, a fim de reconstituir tanto quanto possível o tecido social variado e conflituoso que deu forma a estas ações, que se repartiram entre várias regiões do Continente, Ilhas e alguns territórios de emigração (em especial em França p. 219). Dotando-se de métodos de pesquisa mistos - entrevistas profundas, trabalho de arquivo (em arquivos públicos e particulares), trabalho de campo (com deslocação a alguns dos locais intervencionados) - o que nos é apresentado é uma espécie de etnografia da memória dessas campanhas (a autora chama-lhe "etnografia retrospetiva" ou "por recuo"- p. 46), que cruza, com notável agilidade, as várias memórias individuais e o processo de formação, instável e em permanente conflito, de uma memó- 
ria coletiva. Para além do amplo recurso a arquivos (equiparados a um "terreno antropológico" - p. 48) e a fontes bibliográficas que lhe permitem elaborar um quadro contextual bastante claro e preciso, a autora serve-se profusamente das entrevistas realizadas a algumas dezenas de participantes nessas campanhas - membros das Forças Armadas, de várias patentes e funções, artistas e civis de diversas áreas profissionais. A estas são adicionados testemunhos locais - maioritariamente (por razões que a autora justifica - pp. 31-32, 54) do concelho de Castro Daire.

O livro divide-se em quatro partes: (1) "Camponeses, antropologia e revolução" (pp. 27-55), que insere o presente estudo no quadro geral da antropologia portuguesa e internacional, centrando-se sobre o nexo "povo-ruralidade" e "povo-revolução" e procurando responder ao relativo desinteresse da antropologia (ao contrário de outras áreas, como a história, a sociologia e a ciência política) por este período; (2) "A construção do Portugal revolucionário e a integração do povo na sociedade portuguesa" (pp. 59-241), a parte central da obra, que faz uma análise bastante completa das campanhas do MFA - desde as suas origens imediatas, que entroncam em iniciativas (civis e militares) já existentes, à sua organização formal, reestruturação e implementação no terreno, incluindo a descrição de algumas das principais "operações”, suas trajetórias e formas de atuação; (3) "Imagens do povo na revolução" (pp. 245-342), que retoma um tópico privilegiado da antropologia portuguesa (o povo e a cultura popular) para discutir as representações pós-revolucionárias desta categoria que, para além de se oporem à "imagem coreografada da nação" (p. 249) forjada pelo Estado Novo, passam a ser "reinventadas" à luz de uma "pastoral" e de uma "contrapastoral" revolucionárias; (4) "Discurso local sobre as Campanhas de Dinamização
Cultural e Ação Cívica do MFA" (pp. 345-381), que procura destrinçar, como o título indica, as perspetivas locais, a partir das povoações que a autora visitou e estudou mais aprofundadamente.

Não há dúvida de que o enfoque deste estudo são os discursos - as "leituras que sobre Portugal foram feitas e que legitimaram uma ação específica" (p. 47); as várias "construções discursivas" da época que alimentaram a(s) memória(s) (p. 83); em suma, o modo como estes "discursos" participaram no mapeamento e remapeamento ideológico (o termo é meu, não da autora) de temas-chave, como ruralidade, povo, nação, ou mesmo revolução. Procurando descrever a "paisagem discursiva sobre Portugal" (p. 251) que caracterizou estes anos, a autora centra-se na análise de processos eminentemente discursivos, como a "retórica da visibilidade" (pp. 29, 268) - sublinhando a intenção das campanhas de "desvelarem" o país (um verbo recorrente)-, as "lutas de classificação" (segundo a terminologia de Bourdieu, p. 31), a "ressemantização" do conceito de povo (p. 252). Este interesse pelo discurso não surpreende, dada a centralidade das fontes textuais, orais e escritas, formais e informais (incluindo o boato e o rumor - p. 212), na investigação, bem como a conceção construtivista, não substancialista, da realidade, que a autora adota (p. 30) e que o objeto de estudo amplamente justifica.

No entanto, um enfoque exclusivo nos discursos e nas representações corre o risco de sucumbir a uma visão idealista da história (um risco que a autora, de resto, não deixa de mencionar - nota 1, p. 250). De facto, não são apenas os discursos que atribuem significados às práticas (segundo a formulação de Verdery, cit. p. 31), mas também as práticas que atribuem significados aos discursos. A noção de que os discursos não existem apenas no plano das ideias, mas em articulação constante com 
práticas, num processo de mútua construção e legitimação, não é suficientemente vocalizada, apesar de ser uma das conclusões mais eloquentes do presente estudo. A própria transformação destas campanhas ao longo da sua breve existência (o programa é anunciado a 25 de outubro de 1974 e interrompido no seguimento do 25 de Novembro de 1975, havendo casos em que se manteve no terreno depois disso) reforça esta conclusão. Inicialmente concebidas para "conquistar as Forças Armadas para o movimento" (p. 87), tendo como alvo os próprios militares (pelo menos segundo alguns dos seus protagonistas), as campanhas do MFA rapidamente passaram a centrar-se nas populações mais afastadas da capital, cujo conhecimento dos factos seria escasso, inexistente ou deturpado. O objetivo de prestar esclarecimento sobre o 25 de Abril (a ação pela "palavra") depressa dá lugar ao levantamento e à resolução de problemas imediatos - desencadeando a construção de estradas, pontes e arruamentos, ou outras obras, como a eletrificação, o abastecimento de água, o saneamento básico, etc. (a ação pelos "atos") - uma mudança de ênfase que se traduziu na reinvenção da dinamização cultural em “ação cívica" (p. 256). Nas palavras de um dos principais intervenientes, "encomendava-se ao MFA como a um santo patrono" (cit. p. 189), tornando-se a capacidade de resposta do MFA crucial na luta contra os discursos da "reação".

Por outro lado, a componente cultural - alfabetização e dinamização cultural e artística a nível local - foi ganhando espaço, primeiro como forma estratégica de facilitar o contacto com as populações, depois como um projeto mais autónomo da responsabilidade de artistas e intelectuais, configurando o que, para muitos, era também uma "revolução cultural" (pp. 103, 277, 313-314). A "cultura" tornou-se, com efeito, e como este estudo demonstra, um conceito recorrente, contestado, "apropriado" (p. 275) e "manipulado” (p. 276) no quadro destas campanhas, não sem alguma ambiguidade: sob o signo da "descentralização cultural", tanto se fala da necessidade de "preencher o vácuo cultural", sobretudo de certas zonas (p. 100), como da vontade de criar laços com as associações culturais existentes (p. 101), ou mesmo de preservar (ou "revitalizar" - p. 315) uma cultura local/popular “autêntica” (p. 311). E, apesar do desejo manifesto de evitar "praticar colonialismo cultural” (p. 173), o MFA enfrenta críticas, por um lado, de impreparação, oriundas do Ministério de Educação e Cultura (p. 92) e, por outro, de "dirigismo", oriundas de alguns dos agentes culturais também no terreno. Não sendo de subestimar (nem de sobrestimar) a participação dos intelectuais (um grupo, como nota a autora, heterogéneo - p. 105), a esfera de ação do MFA estendeu-se por diversos setores da sociedade, convergindo com outros movimentos (muitos de iniciativa estatal) que o antecederam ou lhe sucederam, tais como: as campanhas de alfabetização e educação sanitária da Pró-UNEP; as campanhas do SAAL; o Serviço Cívico Estudantil, no qual se inseria o Plano de Trabalho e Cultura de Michel Giacometti; o Serviço Médico à Periferia (de junho de 1975), entre outros.

A terceira parte deste estudo - uma das mais fortes e estimulantes em termos teóricos - trata da questão do povo e da cultura popular. A autora esmiúça os diversos usos a que o conceito de "povo" foi sujeito, inserindo-os ora numa "contrapastoral revolucionária” - que o concebe como "adormecido", "inculto", "assustado", conformado", "atrasado" e "dependente" - ora numa "pastoral revolucionária", que faz o "elogio da ruralidade" (p. 302) a fim de convocar o camponês como "coagente" da revolução (p. 327, 339). A ambiguidade inscrita no conceito de "povo" é eficazmente descrita e teorizada: "povo" 
denota, por um lado, uma totalidade que se quer neutra (a nação) e, por outro, as classes desfavorecidas, que são também as classes trabalhadoras, "exploradas" e em franca oposição à classe dos "exploradores" (p. 253). Como a autora reconhece, não se trata de uma particularidade do contexto português; no entanto, seria importante acrescentar que esta "ambiguidade" é própria de projetos políticos coletivos de cariz universalizante, articulados a partir da perspetiva, até então excluída, de uma "parte sem parte", segundo a proposta teórica de Jacques Rancière (La mésentente, 1995) e Slavoj Žižek (The Ticklish Subject, 1999).

A ser considerada, esta proposta teórica lança dúvidas sobre a asserção (central à tese da autora) de que o MFA privilegiou um entendimento do povo como rural, i.e. camponês e do Norte (pp. 254-255) - uma asserção que é entendida à luz de preocupações centrais, senão mesmo definidoras, da antropologia (como a autora refere no início, o espaço periférico/rural, afastado de casa/da cidade é um dos fatores legitimadores da disciplina - p. 55), mas que poderá ofuscar outros elementos não menos importantes. Um deles é o enquadramento destas campanhas num projeto de modernização (um termo ausente deste estudo), de algum modo contrário ao projeto antropológico (tradicionalmente de "congelamento" ou, pelo menos, de salvamento do que está prestes a ser perdido). Se é certo que as campanhas do MFA convocaram posições muito próximas às da antropologia em relação à ruralidade - manifestando alguns dos seus protagonistas "sensibilidade antropológica" (p. 304) e uma certa "sedução etnográfica" (p. 319) - também é verdade que a "caminhada até às aldeias" se encontrava firmemente alicerçada numa "estratégia de desenvolvimento" mais vasta, que visava "melhorar radicalmente as condições de vida do interior" (cit. p. 262), conduzir a "uma maior igualdade económica" (cit. p. 264) e, desse modo, resolver a "contradição cidade-campo" (cit. p. 262). Este aspeto - que a autora não deixa de analisar - tornou-se mais importante com a decisão do MFA de trocar, depois do 11 de Março de 1975, a via "socializante" por uma via "socialista" (cit. p. 328), e é importante por permitir estabelecer os limites da "semelhança inconfortável com o regime anterior" (p. 320) que a autora deteta em relação à valorização da cultura popular (rural) e suas tradições. Com efeito, subjacente à “caminhada até às aldeias" estava não só a ideia de "descentralização da cultura", assente no encontro com o "outro" e na descoberta de uma cultura "outra" mais autêntica, mas também a ideia de "regionalização do desenvolvimento económico, social e cultural" (cit. p. 273), ou mesmo (o que torna a questão do desenvolvimento ainda mais controversa) de "regionalização dos confortos do capitalismo" (cit. p. 250).

Camponeses, Cultura e Revolução é uma obra de uma acutilância teórica e analítica notável, oferecendo importantes contributos, não só para o tema em si, mas também para as questões teóricas que norteiam o seu estudo. Para além das temáticas e problemáticas já salientadas (relevantes, sobretudo, para a antropologia e para os estudos culturais), acrescente-se o importante contributo que esta obra presta à compreensão e teorização das relações entre o Estado, a chamada "sociedade civil" (incluindo os movimentos sociais) e os partidos. A relação com estes últimos não é um objeto de eleição (p. 239), mas emerge em vários pontos, sobretudo no capítulo 10. É também de salientar o domínio da autora sobre as diversas escalas em que estas campanhas se integraram e através das quais se definiram - nacional, regional, local e internacional. A última está menos presente, mas entrevê-se, por exemplo, na proclamação de uma "especificidade portuguesa", designadamente sob a forma de um "huma- 
nismo português" (p. 93). Recorrendo a um manancial de discursos - destilados de documentos programáticos, comunicados oficiais e conferências de imprensa, de relatórios de ação relativos às várias campanhas (p. 226), ou das "múltiplas vozes" captadas a nível local, que abarcam a imprensa regional e os boletins paroquiais -, a autora consegue delinear um campo de posições que são, apesar das várias contradições, inteligíveis. Alguns relatos em primeira mão contrariam certas ideias feitas (p. 362), mostrando a pertinência dos métodos usados.

Quanto aos aspetos menos satisfatórios desta obra, salientem-se apenas dois: (1) as notas de rodapé, longas e abundantes, que interrompem a leitura com demasiada frequência, e cuja informação, pertinente na maior parte dos casos, poderia ter sido integrada no corpo do texto ou, em casos extremos, remetida para um anexo (ex. nota 118 , pp. 142-143, com os estatutos dos conselhos de aldeia, ou a citação incluída na nota 122 , p. 145, que ocupa a quase totalidade da página); (2) a fraca presença de registos visuais - sobretudo tendo em conta o con-

Charles Westin, José Bastos, Janine Dahinden e Pedro Góis (orgs.) IDENTITY PROCESSES

\section{AND DYNAMICS IN MULTI-ETHNIC EUROPE}

IMISCOE Research series, Amesterdão, Amsterdam University Press, 2010 , 375 páginas, ISBN: 978-90-8964-046-8.

Pensar a(s) diversidade(s) na Europa contemporânea é o objetivo genérico desta coletânea. De que modo se podem estu- tacto da autora com vários acervos desta natureza, a que o texto faz alusão.

De resto, este é um trabalho que merece ser amplamente lido e discutido. Não cedendo a relativismos paralisantes, nem à aporia da complexidade, a autora consegue brindar-nos com um retrato cuidadoso das campanhas do MFA, revelando as suas principais tensões internas e externas, percorridas através de diferentes espaços e temporalidades, e perspetivadas por diferentes atores sociais. Tendo sido, no seu tempo, um dos principais palcos da disputa política, social e cultural, estas campanhas encontram ainda eco na cena política atual, manifestando-se quer na memória (no que a autora designa por "diálogo entre os dois tempos" - p. 385) quer nas lutas, de "classificação" e outras, que continuam a ter lugar nos nossos dias.

\section{Sofia Sampaio}

Centro em Rede de Investigação em Antropologia, ISCTE - Instituto Universitário de Lisboa, Portugal psrss@iscte.pt dar e comparar as relações interétnicas em países europeus com experiências históricas e atuais de diversidade tão distintas? De que modos a Europa tem vindo a governar as diversidades? O que se entende por identidade na atual Europa multiétnica? Como se constroem as identidades e as relações interétnicas? Como desenvolver novas estratégias metodológicas para estudar as identidades?

A coletânea reúne um amplo conjunto de estudos que partem de perspetivas disciplinares tão diversificadas como a da 